\title{
Homocysteine, methylenetetrahydrofolate reductase C677T polymorphism and cognitive impairment: the health in men study
}

\author{
AH Ford ${ }^{1}$, L Flicker ${ }^{2}$, GJ Hankey ${ }^{3}$, P Norman ${ }^{4}$, FM van Bockxmeer ${ }^{5}$ and OP Almeida ${ }^{1}$ \\ ${ }^{1}$ WA Centre for Health and Ageing, Centre for Medical Research and School of Psychiatry and Clinical Neurosciences, \\ University of Western Australia, Perth, WA, Australia; ${ }^{2}$ WA Centre for Health and Ageing, Centre for Medical Research and \\ School of Medicine and Pharmacology, University of Western Australia, Perth, WA, Australia; ${ }^{3}$ School of Medicine and \\ Pharmacology, University of Western Australia, Perth, WA, Australia; ${ }^{4}$ School of Surgery, University of Western Australia, \\ Perth, WA, Australia and ${ }^{5}$ School of Pathology and Laboratory Medicine, University of Western Australia, Perth, WA, Australia
}

\begin{abstract}
High total plasma homocysteine (tHcy) has been associated with cognitive impairment in later life, but it is unclear if this association is causal or is due to confounding. The C677T polymorphism of the 5,10 methylenetetrahydrofolate reductase gene (MTHFR) increases basal tHcy, but its contribution to cognitive impairment has not been established. We designed this study to determine if thcy is causally related to cognitive impairment in later life by investigating its association with high tHcy and the MTHFR-C677T polymorphism. We recruited 1778 older men from the Health in Men Study cohort and established caseness on the basis of the participants' scores on a Telephone Interview for Cognitive Status score $\leqslant \mathbf{2 7}$ in 2008. Exposure to tHcy, gene status and other variables of interest were obtained from assessments 4-7 years earlier. Multivariate logistic regression showed that the odds of cognitive impairment increased with a doubling of tHcy (adjusted odds ratio, OR 1.36; $95 \%$ confidence interval, $95 \% \mathrm{Cl} 1.02-1.82)$. Compared with the wild CC genotype, participants with the MTHFR-TT genotype had $46 \%$ greater odds of cognitive impairment (OR $1.46,95 \% \mathrm{CI}$ 1.01-2.11, $P=0.043$ ). The results of this study are consistent with, but do not prove the hypothesis that high thcy causes cognitive impairment in later life.

Molecular Psychiatry (2012) 17, 559-566; doi:10.1038/mp.2011.18; published online 1 March 2011
\end{abstract}

Keywords: cognition; dementia; homocysteine; methylenetetrahydrofolate reductase gene

\section{Introduction}

Current estimates suggest that over 80 million people worldwide will be affected by dementia by $2040 .^{1}$ This is an alarming prospect, given that treatments seem unable to reverse or halt the deficits associated with this group of diseases. High total plasma homocysteine (tHcy) has been associated with cognitive impairment and dementia in observational studies, offering hope that by reducing tHcy with oral supplementation of specific B-vitamins we may succeed in delaying the progression of cognitive decline and the onset of dementia. ${ }^{2}$

A number of observational studies have reported an association between high tHcy and cognitive impairment, but results to date have been inconsistent and the nature of this research makes it difficult to draw any firm conclusions about causality. ${ }^{3-7}$ For example,

Correspondence: Professor OP Almeida, School of Psychiatry and Clinical Neurosciences (M573), University of Western Australia, 35 Stirling Highway, Crawley, Perth, WA 6009, Australia. E-mail: osvaldo.almeida@uwa.edu.au

Received 29 July 2010; revised 25 January 2011; accepted 30 January 2011; published online 1 March 2011
Luchsinger et $a .^{8}$ found that the risk of incident Alzheimer's disease (AD, the most frequent cause of dementia) was twice as large amongst people in the highest compared with the lowest tHcy quartile (hazard ratio, $\mathrm{HR}=2.0,95 \%$ confidence interval, 95\% $\mathrm{CI}=1.2-3.5$ ), but such an association disappeared once the analyses were adjusted for the joint effects of age, gender, education, apolipoprotein-E status and a history of stroke $(\mathrm{HR}=1.3,95 \% \mathrm{CI}=0.8-2.3)$. In contrast, longitudinal data derived from the Framingham study sample of 1092 people showed that the relative risk of dementia increased by about $40 \%$ (95\% CI $=10-90 \%)$ for each increase of one standard deviation in the log-transformed tHcy concentration. ${ }^{9}$ These analyses were adjusted for age, gender, apolipoprotein-E status, folate, vitamin $\mathrm{B}_{12}$ and $\mathrm{B}_{6}$ and other vascular risk factors.

Randomized trials of homocysteine lowering treatment for older people without dementia have not been able to demonstrate an improvement in cognitive performance associated with the use of B-vitamins, ${ }^{10-12}$ although the largest and longest randomized trial published to date found that the use of folic acid improved cognition compared with placebo. ${ }^{13}$ 
These conflicting findings may be due to negatively-randomized trials recruiting healthy volunteers at low risk of developing cognitive impairment, using B-vitamins of inadequate dose and duration, evaluating cognitive function by means of insensitive or invalid measures and lacking statistical power to reliably detect small, but clinically important effect sizes. To date, no trials have been sufficiently powered to investigate the effect of homocysteine lowering treatment in dementia prevention (rather than small changes in the normal range of cognitive function).

Homocysteine metabolism is dependent on a number of enzymes and vitamin co-factors. Methylenetetrahydrofolate reductase (MTHFR) is an enzyme involved in the remethylation of homocysteine to methionine. A common genetic polymorphism exists in which cytosine is replaced by thymine $(\mathrm{C} \rightarrow \mathrm{T})$ at base position $677 .{ }^{14}$ This polymorphism results in reduced enzymatic activity and a $20 \%$ increase in basal plasma tHcy. ${ }^{15}$ Of note, the TT genotype has been associated with poorer cognitive performance and increased risk of dementia, ${ }^{16-19}$ albeit not consistently. ${ }^{20,21}$ The advantage of examining the MTHFR-C677T polymorphism in people with cognitive impairment is that this association is not confounded by other factors that affect tHcy, such as age, lifestyle, medications and comorbidities. ${ }^{22}$ This approach has been termed Mendelian randomization, as the exposure commences at conception and is unconfounded by environmental factors, effectively producing random exposure to the biological factor of interest. One of the limitations of Mendelian randomization is that other factors may affect the phenotype (in this case, cognitive function) through geneenvironment or gene-gene interactions. As a result, gene-phenotype associations are not simple. Nonetheless, if such a link could be confirmed, this would underscore the validity of the association between high tHcy and cognitive impairment, and would support the use of B-vitamins to decrease the incidence of dementia in later life. ${ }^{23}$

We designed the present study to determine if elevated tHcy and the MTHFR-C677T polymorphism are associated with cognitive impairment in a community sample of 1778 older men. We hypothesized that the odds of cognitive impairment would increase with plasma tHcy and would be greatest in men with tHcy $\geqslant 15 \mu \mathrm{mol} / \mathrm{l}$ and those with the MTHFR-TT genotype.

\section{Methods}

\section{Study design}

This is a case-control study of older men recruited as part of the Health in Men Study cohort. ${ }^{24}$

\section{Setting and participants}

The Health in Men Study originated from a population-based trial of screening for abdominal aortic aneurysm in Perth, Western Australia, between 1996

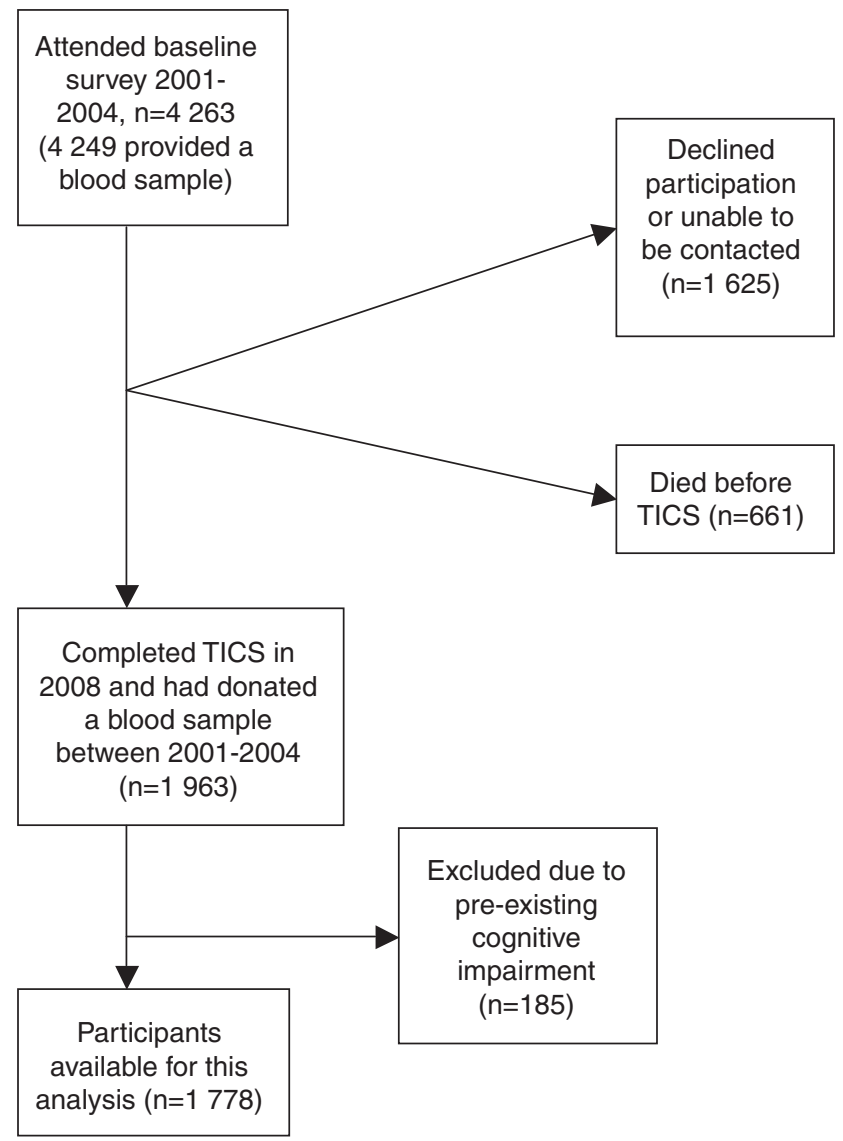

Figure 1 Flow of participants from the time of collection of blood samples to establishment of the presence of cognitive impairment.

and 1998. Between 2001 and 2004, 4249 men completed a health assessment and donated a blood sample (baseline for this study). Men were community-dwelling Australian citizens, recruited through the electoral roll (voting being compulsory in Australia). We excluded participants not fluent in written or spoken English. Surviving participants (661 had died) were contacted from August to December 2008 and invited to complete the Telephone Interview for Cognitive Status (TICS). ${ }^{25}$ We excluded from this assessment men with a total score of 23 or less on the Mini-Mental State Examination (MMSE) at baseline (prevalent cases of cognitive impairment). ${ }^{26}$ Men who survived till 2008 and scored 27 or less on the TICS were selected as the cases and the remaining participants were selected as the controls-they were all free of significant hearing impairment-as determined by their ability to communicate effectively with others on the telephone (for example, able to understand and respond appropriately and promptly to instructions). Figure 1 shows the flow of participants from baseline to the time of assessment with the TICS.

\section{Baseline measurements of exposure to tHcy}

We collected fasting blood samples from participants at baseline between 0830 and $1100 \mathrm{~h}$. Plasma and 
serum were separated from blood cells within $1 \mathrm{~h}$ of blood collection and stored at $-80^{\circ} \mathrm{C}$ until assayed. Total plasma homocysteine concentration was determined by reverse-phase high-performance liquid chromatography after treatment with tributylphosphine, deproteinization and fluorogenic derivatization, using the method of Araki and Sako. ${ }^{27}$ The coefficient of variation ranged from 3 to $7 \%$. Men with tHcy $\geqslant 15 \mu \mathrm{mol} / \mathrm{l}$ were considered to have high tHcy.

Genomic DNA was isolated from nucleated blood cells through a Triton X-100 method, and the C677T polymorphism determined using polymerase chain reaction and HinfI restriction enzyme digestion, as previously described. ${ }^{28}$ HinfI digestion (1.5-U/25 $\mu \mathrm{l}$ reaction mixture) was performed directly in the polymerase chain reaction tube at $37^{\circ} \mathrm{C}$ for $4 \mathrm{~h}$, before analysis of restriction fragments by polyacrylamide gel electrophoresis $(12 \% \mathrm{~T}, 3.3 \% \mathrm{C})$. Allele frequencies were estimated by gene counting, and observed numbers of each genotype were compared with those expected under the Hardy-Weinberg equilibrium.

\section{Other baseline measures}

At the baseline assessment, we used standard procedures to collect the following information from participants: age (in years), highest educational achievement, smoking (past or current), risky alcohol use ( $\geqslant 15$ standard units per week), physical activity $(\geqslant 150 \mathrm{~min}$ per week of vigorous or non-vigorous physical activity) and physician diagnosis of stroke, diabetes, ischemic heart disease, head injury or hypertension. We used the 15-item Geriatric Depression Scale (GDS-15) ${ }^{29}$ to assess depressive symptoms and measured blood pressure (within $2 \mathrm{~mm} \mathrm{Hg}$ ), height (in meters, to $0.01 \mathrm{~m}$ ) and weight (in $\mathrm{kg}$, to $0.1 \mathrm{~kg}$ ). We calculated the body mass index (BMI) in $\mathrm{kg} / \mathrm{m}^{2}$.

Fasting blood samples were used to measure serum glucose, thyroid stimulating hormone, cholesterol, low-density lipoprotein and triglycerides with a Roche Hitachi 917 analyzer (Roche Diagnostics). Serum triglycerides were estimated by the Friedewald equation. ${ }^{30}$ Serum creatinine was measured by Jaffe kinetic reaction on a Roche 917 analyzer, and the estimated glomerular filtration rate was calculated using the Cockcroft-Gault equation:

$$
[(140-\text { age }) \times w t(k g)] /(\text { plasma creatinine } \times 0.8136) .
$$

\section{Outcomes}

The primary outcome of interest in this study was cognitive impairment, as defined by a total score of 27 or less on the TICS, as measured in 2008.

\section{Statistical analysis}

Data was analyzed with the statistical package Stata 11.1 (StataCorp 2009, TX, USA). Descriptive statistics were used to analyze cross-sectional data, reporting these as frequencies (\%) and means with standard

deviations. Student $t$-tests were used in the analysis of normally distributed data, the Mann-Whitney $U$ tests in the analysis of ranked data and chi-square tests to compare proportions between groups. Analysis of variance was used to compare differences between the MTHFR genotypes for continuous variables. Skewed data (age, tHcy, GDS, triglycerides and thyroid stimulating hormone) were log-transformed to perform the analysis of variance and reported as the geometric mean. Multivariate logistic regression was used to investigate the association between tHcy and cognitive impairment, and the results are reported as ORs with 95\% confidence limits. Three models were used: the first contained no adjustments (crude model), the second model was adjusted for age and education only, and the final model was adjusted for all measured factors described above.

Total plasma homocysteine was included as a continuous variable and dichotomized into plasma concentrations $\geqslant 15 \mu \mathrm{mol} / \mathrm{l}$ compared to those with tHcy $<15 \mu \mathrm{mol} / \mathrm{l}$. As tHcy was positively skewed, we transformed these values into binary logs by dividing the natural log-transformed value of tHcy by the natural $\log$ of 2. Logistic regression performed using these values will give ORs for a doubling of tHcy. We tested the genotype distribution of MTHFR for deviations from the Hardy-Weinberg equilibrium using the exact method.

Total plasma homocysteine increases markedly with age, ${ }^{31}$ therefore quartiles were defined in an age-specific manner for each of the four 5-year age categories (that is, 75-79 (reference), 80-84, 85-90 and $90+$ ). We used multivariate logistic regression to analyze these age-specific quartiles using the lowest quartile as the reference group. Finally, we performed a logistic regression analysis to determine the odds of cognitive impairment according to MTHFR-C677T genotypes (CC genotype used as reference).

\section{Results}

\section{Participants}

A total of 1778 men were included in this study. Of these, 431 men scored $\leqslant 27$ on the TICS (cases of cognitive impairment). All other available participants were included in this study as controls.

\section{Cross-sectional data}

Characteristics of the study population are shown in Table 1. Men with cognitive impairment were on average 1.5 years older $(\mathrm{z}=-7.21, P<0.001)$. They were also less educated $\left(\chi^{2}=53.44, P<0.001\right)$, had more depressive symptoms $(\mathrm{z}=-4.07, P<0.001)$ and were more likely to report a history of diabetes $\left(\chi^{2}=8.34, \quad P=0.004\right)$ and hypertension $\left(\chi^{2}=6.47\right.$, $P=0.011)$. The mean tHcy was $0.7 \mu \mathrm{mol} / \mathrm{l}$ lower in controls $(\mathrm{z}=-3.75, P<0.001)$. In all, 376 men $(21.1 \%)$ had high tHcy and this was more frequent in participants with cognitive impairment $\left(\chi^{2}=8.77\right.$, $P=0.003$ ). The groups were comparable for other measured factors, such as physical activity, history of 
Table 1 Cross-sectional characteristics of the study population

\begin{tabular}{|c|c|c|c|c|}
\hline Variable & Controls $(\mathrm{n}=1347)$ & Cases $(\mathrm{n}=431)$ & Statistic & $\mathrm{P}$ value \\
\hline Age, mean (s.d.) years & $81.2(3.5)$ & $82.7(3.9)$ & $\mathrm{z}=-7.21$ & $<0.001$ \\
\hline Education, $n(\%)$ completed high school or better & $807(59.9)$ & $171(39.7)$ & $\chi^{2}=53.44$ & $<0.001$ \\
\hline Physical activity, $n(\%)$ & $942(69.9)$ & $284(66.0)$ & $\chi^{2}=2.30$ & 0.129 \\
\hline Smoking, $n(\%)$ & $838(62.2)$ & $285(66.1)$ & $\chi^{2}=2.15$ & 0.143 \\
\hline Alcohol, $n(\%)$ & $459(34.1)$ & $136(31.6)$ & $\chi^{2}=0.93$ & 0.334 \\
\hline GDS, mean (s.d.) & $1.61(1.76)$ & $2.11(2.3)$ & $\mathrm{z}=-4.07$ & $<0.001$ \\
\hline History stroke, $n(\%)$ & $62(4.6)$ & $28(6.5)$ & $\chi^{2}=2.44$ & 0.119 \\
\hline History diabetes, $n(\%)$ & $107(7.9)$ & $54(12.5)$ & $\chi^{2}=8.34$ & 0.004 \\
\hline History IHD, $n(\%)$ & $123(9.1)$ & $43(10)$ & $\chi^{2}=0.28$ & 0.600 \\
\hline History hypertension, $n(\%)$ & $341(25.3)$ & $136(31.6)$ & $\chi^{2}=6.47$ & 0.011 \\
\hline History of head injury, $n(\%)$ & $207(15.5)$ & $66(15.5)$ & $\chi^{2}=0$ & 1.000 \\
\hline BMI, mean (s.d.) & $26.5(3.4)$ & $26.5(3.4)$ & $t=-0.00$ & 0.999 \\
\hline Systolic BP, mean (s.d.) mm mercury & $147.2(20.1)$ & $147.9(21.2)$ & $t=-0.61$ & 0.541 \\
\hline Diastolic BP, mean (s.d.) mm mercury & $75.4(10.2)$ & $75.2(11.3)$ & $t=0.37$ & 0.714 \\
\hline Glomerular filtration rate, mean (s.d.) $\mathrm{ml} / \mathrm{min}$ & $78.5(18.3)$ & $77.8(18.3)$ & $t=0.46$ & 0.229 \\
\hline Cholesterol, mean (s.d.) mmol/l & $4.9(0.9)$ & $4.9(0.9)$ & $t=0.39$ & 0.806 \\
\hline Low density lipoprotein, mean (s.d.) mmol/l & $2.9(0.8)$ & $2.9(0.8)$ & $t=0.42$ & 0.790 \\
\hline Triglycerides, mean (s.d.) mmol/l & $1.3(0.7)$ & $1.4(.8)$ & $\mathrm{z}=-0.38$ & 0.701 \\
\hline Glucose, mean (s.d.) $\mathrm{mmol} / \mathrm{l}$ & $5.7(1.4)$ & $5.7(1.4)$ & $t=0.44$ & 0.663 \\
\hline TSH, mean (s.d.) mU/l & $2.3(1.5)$ & $2.5(2)$ & $\mathrm{z}=-0.91$ & 0.364 \\
\hline tHcy, mean (s.d.) $\mu \mathrm{mol} / \mathrm{l}$ & $12.6(4.8)$ & $13.3(4.5)$ & $\mathrm{z}=-3.75$ & $<0.001$ \\
\hline
\end{tabular}

Abbreviations: BMI, body mass index; BP, blood pressure; GDS, geriatric depression scale; IHD, ischemic heart disease; tHcy, total plasma homocysteine; TSH, thyroid stimulating hormone.

stroke, head injury and ischemic heart disease, smoking, alcohol use, lipid profile and BMI.

\section{Main results}

The distribution of the MTHFR polymorphism was similar for each of the groups: CC $564(46.2 \%)$, CT 531 $(43.5 \%)$ and TT $127(10.4 \%)$ in the controls and CC $158(41.8 \%)$, CT $168(44.4 \%)$ and TT $52(13.8 \%)$ in the cases $\left(\chi^{2}=4.20, P=0.123\right)$. Baseline characteristics were equally distributed across the MTHFR-C677T genotypes (Table 2). Mean tHcy concentration varied according to the MTHFR genotype: $11.8 \pm 1.3 \mu \mathrm{mol} / \mathrm{l}$, $12.3 \pm 1.4 \mu \mathrm{mol}$ and $12.5 \pm 1.5 \mu \mathrm{mol} / \mathrm{l}$ for men with the CC, CT and TT genotype, respectively $(\mathrm{F}=4.77$, $P=0.009$ ). The distribution of MTHFR-C677T genotypes was as expected, given the Hardy-Weinberg equilibrium test $(P=0.504$ for cases and $P=0.896$ for controls).

The odds of cognitive impairment increased with every $1 \mu \mathrm{mol} / \mathrm{l}$ increase of tHcy (OR 1.03, 95\% CI 1.01-1.05, $P=0.006$ ) (Table 3). Individuals with elevated tHcy were also more likely to develop cognitive impairment (OR 1.47, 95\% CI 1.14-1.89, $P=0.003)$. The odds of cognitive impairment increased with a doubling of tHcy (OR 1.59, 95\% CI 1.24-2.03, $P<0.001$ ), and this association remained significant after adjustments were made for age and education (OR 1.37, 95\% CI 1.06-1.78) and other measured factors (OR 1.36, 95\% CI 1.02-1.82). Participants with the MTHFR-TT genotype had greater odds of cognitive impairment (OR 1.46, 95\% CI $1.01-2.11, P=0.043)$ compared with the CC genotype.
The 75th percentile of tHcy for each 5-year age group was as follows: $75-79(13.6 \mu \mathrm{mol} / \mathrm{l}), 80-84$ $(14.7 \mu \mathrm{mol} / \mathrm{l}), \quad 85-89 \quad(16.0 \mu \mathrm{mol} / \mathrm{l})$ and $90+$ $(15.9 \mu \mathrm{mol} / \mathrm{l})$. Men in the highest tHcy quartile of their specific age group (lowest quartile as reference group) had $40 \%$ higher odds of cognitive impairment (OR 1.40; 95\% CI 1.03-1.91, $P=0.032$ ). This difference remained significant after adjustment for all measured factors (OR 1.59, 95\% CI 1.10-2.28).

\section{Post-hoc analysis}

We performed post-hoc analyses to clarify if any bias was introduced because of the loss of men through non-participation or death. Participants who died before participation in the TICS $(n=661)$ were on average 2.8 years older $(\mathrm{z}=-15.23, P<0.001)$, had higher mean tHcy concentrations (15.3 vs $12.8 \mu \mathrm{mol} / \mathrm{l}$, $\mathrm{z}=-9.76, P<0.001)$ and lower mean MMSE scores at the time of blood collection $(25.9$ vs $27.3, t=14.39$, $P<0.001)$ than those who completed the TICS. Similarly, compared with men who completed the TICS, men who were still alive but declined participation $(n=1625)$ were older $(77.0$ vs 76.3 years, $\mathrm{z}=5.14, P<0.001)$, had higher tHcy concentrations (13.4 vs $12.8 \mu \mathrm{mol} / \mathrm{L}, \mathrm{z}=4.52, P<0.001$ ) and lower MMSE scores at the time of blood sampling (27.0 vs 27.3, $t=-4.59, P<0.001)$.

\section{Discussion}

The results of this study are consistent with the hypothesis that high tHcy causes cognitive impairment in later life. We found that the doubling of tHcy 
Table 2 Cross-sectional characteristics of the study population according to MTHFR genotype

\begin{tabular}{|c|c|c|c|c|c|}
\hline Variable & $C C(\mathrm{n}=722)$ & $C T(\mathrm{n}=699)$ & $T T(\mathrm{n}=179)$ & Statistic & $\mathrm{P}$ value \\
\hline Age, mean (s.d.) years & $81.3(1.0)$ & $81.8(1.0)$ & $81.5(1.0)$ & $\mathrm{F}=2.89$ & 0.056 \\
\hline Education, $n(\%)$ & $399(55.3)$ & $393(56.2)$ & $91(50.8)$ & $\chi^{2}=1.67$ & 0.433 \\
\hline Physical activity, $n(\%)$ & $508(70.4)$ & $477(68.2)$ & $129(72.1)$ & $\chi^{2}=1.32$ & 0.516 \\
\hline Smoking, $n(\%)$ & $436(60.4)$ & $459(65.7)$ & $114(63.7)$ & $\chi^{2}=4.28$ & 0.118 \\
\hline Alcohol, $n(\%)$ & $246(34.1)$ & $235(33.6)$ & $54(30.2)$ & $\chi^{2}=1.00$ & 0.606 \\
\hline GDS, mean (s.d.) & $1.6(1.8)$ & $1.6(1.9)$ & $1.6(1.8)$ & $\tilde{F}=1.33$ & 0.264 \\
\hline History stroke, $n(\%)$ & $40(5.5)$ & $31(4.4)$ & $10(5.6)$ & $\chi^{2}=1.02$ & 0.601 \\
\hline History diabetes, $n(\%)$ & $69(9.6)$ & $69(9.9)$ & $9(5.1)$ & $\chi^{2}=4.22$ & 0.121 \\
\hline History IHD, $n(\%)$ & $66(9.1)$ & $64(9.2)$ & $19(10.6)$ & $\chi^{2}=0.40$ & 0.817 \\
\hline History hypertension, $n(\%)$ & $200(27.7)$ & $180(25.8)$ & $46(25.7)$ & $\chi^{2}=0.78$ & 0.677 \\
\hline History of head injury, $n(\%)$ & $114(15.9)$ & $102(14.8)$ & $24(13.6)$ & $\chi^{2}=0.70$ & 0.705 \\
\hline BMI, mean (s.d.) & $26.4(3.5)$ & $26.8(3.5)$ & $26.5(3.1)$ & $\tilde{F}=2.57$ & 0.077 \\
\hline Systolic BP, mean (s.d.) mm mercury & $147.3(20.4)$ & $147.2(20.4)$ & $147.8(20.9)$ & $\mathrm{F}=0.07$ & 0.935 \\
\hline Diastolic BP, mean (s.d.) mm mercury & $75.1(10.3)$ & $75.4(10.4)$ & $75.2(11.5)$ & $\mathrm{F}=0.17$ & 0.844 \\
\hline Glomerular filtration rate, mean (s.d.) $\mathrm{ml} / \mathrm{min}$ & $78.1(16.7)$ & $78.7(20.0)$ & $78.0(18.2)$ & $\mathrm{F}=0.21$ & 0.814 \\
\hline Cholesterol, mean (s.d.) mmol/l & $4.9(1.0)$ & $4.9(0.9)$ & $4.9(0.9)$ & $\mathrm{F}=0.54$ & 0.583 \\
\hline Low density lipoprotein, mean (s.d.) mmol/l & $2.9(0.8)$ & $2.9(0.8)$ & $2.9(0.8)$ & $\mathrm{F}=0.27$ & 0.765 \\
\hline Triglycerides, mean (s.d.) mmol/l & $1.2(1.6)$ & $1.2(1.6)$ & $1.2(1.6)$ & $\mathrm{F}=1.84$ & 0.159 \\
\hline Glucose, mean (s.d.) mmol/l & $5.7(1.4)$ & $5.7(1.5)$ & $5.7(1.2)$ & $\mathrm{F}=0.21$ & 0.811 \\
\hline TSH, mean (s.d.) mU/l & $2.0(1.9)$ & $2.0(2.0)$ & $1.8(2.4)$ & $\mathrm{F}=1.30$ & 0.272 \\
\hline tHcy, mean (s.d.) $\mu \mathrm{mol} / \mathrm{l}$ & $11.8(1.3)$ & $12.3(1.4)$ & $12.5(1.5)$ & $\mathrm{F}=4.77$ & 0.009 \\
\hline
\end{tabular}

Abbreviations: BMI, body mass index; BP, blood pressure; GDS, geriatric depression scale; IHD, ischemic heart disease; MTHFR, methylenetetrahydrofolate reductase gene; tHcy, total plasma homocysteine; TSH, thyroid stimulating hormone.

Table 3 Odds ratios (95\% CI) of cognitive impairment according to tHcy and gene status

\begin{tabular}{llll}
\hline & Crude model & Adjusted for age and education $^{\text {Fully adjusted }}$ \\
\hline tHcy & $1.03(1.01-1.05)^{\mathrm{b}}$ & $1.02(0.99-1.04)$ & $1.02(0.99-1.04)$ \\
Doubling of tHcy & $1.59(1.24-2.03)^{\mathrm{b}}$ & $1.37(1.06-1.78)^{\mathrm{b}}$ & $1.36(1.02-1.82)^{\mathrm{b}}$ \\
tHcy $\geqslant 15 \mu$ mol/l & $1.47(1.14-1.89)^{\mathrm{b}}$ & $1.28(0.98-1.67)$ & $1.33(0.99-1.78)$ \\
tHcy quartile 2 & $1.10(0.80-1.51)$ & $1.19(0.86-1.64)$ & $1.36(0.96-1.91)$ \\
tHcy quartile 3 & $1.35(0.99-1.84)$ & $1.37(0.99-1.87)$ & $1.43(1.02-2.01)^{\mathrm{b}}$ \\
tHcy quartile 4 & $1.40(1.03-1.91)^{\mathrm{b}}$ & $1.43(1.04-1.96)^{\mathrm{b}}$ & $1.59(1.10-2.28)^{\mathrm{b}}$ \\
MTHFR CT & $1.13(0.88-1.45)$ & & \\
MTHFR TT & $1.46(1.01-2.11)^{\mathrm{b}}$ & & \\
\hline
\end{tabular}

Abbreviations: MTHFR, methylenetetrahydrofolate reductase gene; tHcy, high total plasma homocysteine.

${ }^{a}$ Adjusted for age, education, depressive symptoms, physical activity, history of stroke, diabetes, ischemic heart disease and hypertension, smoking, alcohol, head injury, renal function, thyroid function, serum cholesterol, low density lipoprotein and triglycerides, fasting blood glucose, body mass index (bmi) and blood pressure at baseline (systolic and diastolic).

${ }^{\mathrm{b}} \mathrm{P}<0.05$.

concentration was associated with a $36 \%$ increase in the odds of cognitive impairment in men over the age of 75 years, which was also $59 \%$ higher in men in the upper quartile of tHcy compared with those in the lowest quartile. In addition, we found that men with the TT genotype of the MTHFR gene, which increases basal tHcy, had $46 \%$ higher odds of cognitive impairment than men with the CC genotype.

This study consists of a large community-based sample with a relatively high number of cases, thus giving the study sufficient power to investigate the specified hypotheses. Limitations of this study include the observational nature of the associations, the inclusion of only men in the sample (although there is no suggestion to date that tHcy may have a gender-specific effect with regards to cognition), confounding (for example, diet and use of Bvitamins), and the possibility of reverse causality (that is, changes in lifestyle amongst prevalent cases of cognitive impairment that lead to high tHcy). We attempted to minimize confounding by adjusting our analyses for factors known to affect tHcy and dementia risk (for example, age, gender, smoking, education, alcohol use, etc.). We addressed the problem of reverse causality in two different ways: (1) by excluding from the analyses people with evidence of cognitive impairment at the time of entry into the study and (2) by investigating the association 
between a genetic polymorphism that increases basal tHcy and the development of cognitive impairment. In both instances, our results suggest that high tHcy is causally related to cognitive impairment.

It is possible that bias may have been introduced because of the high number of men on whom baseline assessments were done, but were unavailable for the TICS assessment (53.8\%). These men were older, had higher tHcy concentrations and worse cognitive function than those who completed the TICS. Hence, our results may have been biased towards the null hypothesis and this could have led to an underestimation of the effect-high tHcy on cognitive impairment over time.

It is also conceivable that, by chance, our participants with high tHcy had other characteristics that rendered them more vulnerable to cognitive decline, such as the presence of the apolipoprotein-E genotype. As we did not collect such information, we are unable to dismiss such a possibility outright. Moreover, we acknowledge that our definition of 'caseness' was based on a telephone-screening test for cognitive impairment that, although sensitive, does not equate to the clinical diagnosis of dementia. ${ }^{25}$ Additionally, the assessment of the exposure occurred only once, and we were unable to take into account changes in tHcy that may have taken place over time, although presence of the MTHFR-C677T polymorphism is consistent with prolonged exposure to higher basal tHcy. Furthermore, there is evidence that a single baseline measurement may underestimate the risk of the outcome, because of regression dilution bias, ${ }^{32}$ so that our findings may be conservative. Finally, as assessment with TICS was only available at the follow-up assessment, we are unable to comment on the potential impact of tHcy on cognitive decline over time.

Case-control studies investigating this association have reported similar results. ${ }^{33,34}$ Clarke and colleagues examined 164 patients aged 55 years or older with a clinical diagnosis of Alzheimer's dementia, including 76 with histologically confirmed disease and compared these to 108 age-matched healthy volunteers. Participants in the upper tertile ( $>14 \mu \mathrm{mol} / \mathrm{l}$ ) of tHcy were twice as likely to have $\mathrm{AD}$ compared with people in the lowest tertile and four and a half times more likely to have histologically confirmed AD.

There may be a number of biological pathways by which hyperhomocysteinemia causes cognitive impairment and dementia. Elevated plasma homocysteine may be neurotoxic, an effect possibly mediated by the activation of the N-methyl-D-aspartate receptor. ${ }^{35}$ Homocysteine is also a known risk factor for cardiovascular disease, ${ }^{36}$ having been implicated in the causation of coronary artery disease, carotid atherosclerosis and stroke. ${ }^{37}$ Cardiovascular disease is an important risk factor for both vascular dementia and $\mathrm{AD}$ and may represent yet another mechanism linking high plasma homocysteine to cognitive impairment in later life. ${ }^{38}$ In addition, methionine is the immediate precursor of S-adenosylmethionine, the methyl donor of numerous methylation reactions in the brain. This includes the methylation of phospholipids, nucleic acids, myelin and catecholamines. ${ }^{39}$ Homocysteine also appears to interact with the amyloid and tau pathways implicated in the pathophysiology of AD. ${ }^{40,41}$ Finally, high tHcy may contribute to accelerate ageing, with experimental evidence indicating that the lifespan of rats can be extended through the use of a methionine deficient diet. $^{42}$

The finding of an association between high tHcy and cognitive impairment could have important clinical consequences, as tHcy can be reliably and safely reduced by the simple supplementation of Bvitamins. ${ }^{43} \mathrm{~A}$ number of mostly negative randomized trials have investigated the association between vitamin supplementation and cognitive decline in people with and without dementia, although no trial to date has examined whether the use of B-vitamins can reduce the incidence of dementia in people at risk. ${ }^{10-13,44-46}$

This study has investigated the association between tHcy and cognition in a large sample of elderly men while controlling for a range of potential confounders of the relationship and, additionally, by investigating the association between the MTHFR-genetic polymorphism and cognition. Despite this, the best way to try and definitively investigate the association between the two is through appropriately powered randomized trials. There would be merit in large population-based randomized trials of sufficient duration, with the aim of establishing whether homocysteine lowering with B-vitamins is able to reduce the incidence of dementia.

\section{Conflict of interest}

The authors declare no conflict of interest.

\section{Acknowledgments}

The Health in Men Study is supported by National Health and Medical Research Council of Australia project grants $(964145,139093,403963$ and 455811) with additional funding from the National Heart Foundation and the Western Australian Health Promotion Foundation (Healthway). We thank all the men who participated in the trial and Dr Helman Alfonso (MD) for his advice on study design.

\section{References}

1 Ferri CP, Prince M, Brayne C, Brodaty H, Fratiglioni L, Ganguli M et al. Global prevalence of dementia: a Delphi consensus study. Lancet 2005; 366: 2112-2117.

2 Homocysteine Lowering Trialists' Collaboration. Lowering blood homocysteine with folic acid based supplements: meta-analysis of randomised trials. BMJ 1998; 316: 894-898.

3 Smith AD. The worldwide challenge of the dementias: a role for B vitamins and homocysteine? Food Nutr Bull 2008; 29: S143-S172. 
4 McCaddon A. Homocysteine and cognition-a historical perspective. J Alzheimers Dis 2006; 9: 361-380.

5 Nilsson K, Gustafson L, Faldt R, Andersson A, Brattstrom L, Lindgren A et al. Hyperhomocysteinaemia-a common finding in a psychogeriatric population. Eur J Clin Invest 1996; 26: 853-859.

6 Quadri P, Fragiacomo C, Pezzati R, Zanda E, Forloni G, Tettamanti $\mathrm{M}$ et al. Homocysteine, folate, and vitamin B-12 in mild cognitive impairment, Alzheimer disease, and vascular dementia. Am J Clin Nutr 2004; 80: 114-122.

7 Zylberstein DE, Lissner L, Bjorkelund C, Mehlig K, Thelle DS, Gustafson D et al. Midlife homocysteine and late-life dementia in women. A prospective population study. Neurobiol Aging 2009; e-pub 31 March 2009; doi:10.1016/j.neurobiolaging.2009.02.024.

8 Luchsinger JA, Tang MX, Shea S, Miller J, Green R, Mayeux R. Plasma homocysteine levels and risk of Alzheimer disease. Neurology 2004; 62: 1972-1976.

9 Seshadri S, Beiser A, Selhub J, Jacques PF, Rosenberg IH, D'Agostino RB et al. Plasma homocysteine as a risk factor for dementia and Alzheimer's disease. N Engl J Med 2002; 346: 476-483.

10 Stott DJ, MacIntosh G, Lowe GD, Rumley A, McMahon AD, Langhorne $\mathrm{P}$ et al. Randomized controlled trial of homocysteinelowering vitamin treatment in elderly patients with vascular disease. Am J Clin Nutr 2005; 82: 1320-1326.

11 Eussen SJ, de Groot LC, Joosten LW, Bloo RJ, Clarke R, Ueland PM et al. Effect of oral vitamin B-12 with or without folic acid on cognitive function in older people with mild vitamin B-12 deficiency: a randomized, placebo-controlled trial. Am J Clin Nutr 2006; 84: 361-370.

12 McMahon JA, Green TJ, Skeaff CM, Knight RG, Mann JI, Williams SM. A controlled trial of homocysteine lowering and cognitive performance. N Engl J Med 2006; 354: 2764-2772.

13 Durga J, van Boxtel MP, Schouten EG, Kok FJ, Jolles J, Katan MB et al. Effect of 3-year folic acid supplementation on cognitive function in older adults in the FACIT trial: a randomised, double blind, controlled trial. Lancet 2007; 369: 208-216.

14 Klerk M, Verhoef P, Clarke R, Blom HJ, Kok FJ, Schouten EG. MTHFR $677 \mathrm{C}->\mathrm{T}$ polymorphism and risk of coronary heart disease: a meta-analysis. JAMA 2002; 288: 2023-2031.

15 Frosst P, Blom HJ, Milos R, Goyette P, Sheppard CA, Matthews RG et al. A candidate genetic risk factor for vascular disease: a common mutation in methylenetetrahydrofolate reductase. Nat Genet 1995; 10: 111-113.

16 Elkins JS, Johnston SC, Ziv E, Kado D, Cauley JA, Yaffe K. Methylenetetrahydrofolate reductase C677T polymorphism and cognitive function in older women. Am J Epidemiol 2007; 166: 672-678.

17 McIlroy SP, Dynan KB, Lawson JT, Patterson CC, Passmore AP Moderately elevated plasma homocysteine, methylenetetrahydrofolate reductase genotype, and risk for stroke, vascular dementia, and Alzheimer disease in Northern Ireland. Stroke 2002; 33: 2351-2356.

18 Bi XH, Zhao HL, Zhang ZX, Zhang JW. Association of RFC1 A80G and MTHFR C677T polymorphisms with Alzheimer's disease. Neurobiol Aging 2009; 30: 1601-1607.

19 Li K, Liu S, Yao S, Wang B, Dai D, Yao L. Interaction between interleukin-8 and methylenetetrahydrofolate reductase genes modulates Alzheimer's disease risk. Dement Geriatr Cogn Disord 2009; 27: 286-291.

20 Bottiglieri T, Parnetti L, Arning E, Ortiz T, Amici S, Lanari A et al. Plasma total homocysteine levels and the C677T mutation in the methylenetetrahydrofolate reductase (MTHFR) gene: a study in an Italian population with dementia. Mech Ageing Dev 2001; 122: 2013-2023.

21 Almeida OP, Flicker L, Lautenschlager NT, Leedman P, Vasikaran $S$, van Bockxmeer FM. Contribution of the MTHFR gene to the causal pathway for depression, anxiety and cognitive impairment in later life. Neurobiol Aging 2005; 26: 251-257.

22 Hankey GJ, Eikelboom JW, Ho WK, van Bockxmeer FM. Clinical usefulness of plasma homocysteine in vascular disease. Med J Aust 2004; 181: 314-318.

23 Davey Smith G, Ebrahim S. 'Mendelian randomization': can genetic epidemiology contribute to understanding environmental determinants of disease? Int J Epidemiol 2003; 32: 1-22.

24 Norman PE, Flicker L, Almeida OP, Hankey GJ, Hyde Z, Jamrozik K. Cohort Profile: The Health In Men Study (HIMS). Int J Epidemiol 2009; 38: 48-52.

25 Knopman DS, Roberts RO, Geda YE, Pankratz VS, Christianson TJ, Petersen RC et al. Validation of the telephone interview for cognitive status-modified in subjects with normal cognition, mild cognitive impairment, or dementia. Neuroepidemiology 2010; 34: $34-42$.

26 Folstein MF, Folstein SE, McHugh PR. 'Mini-mental state'. A practical method for grading the cognitive state of patients for the clinician. J Psychiatr Res 1975; 12: 189-198.

27 Araki A, Sako Y. Determination of free and total homocysteine in human plasma by high-performance liquid chromatography with fluorescence detection. J Chromatogr 1987; 422: 43-52.

28 van Bockxmeer FM, Mamotte CD, Vasikaran SD, Taylor RR. Methylenetetrahydrofolate reductase gene and coronary artery disease. Circulation 1997; 95: 21-23.

29 Yesavage JA, Brink TL, Rose TL, Lum O, Huang V, Adey M et al. Development and validation of a geriatric depression screening scale: a preliminary report. J Psychiatr Res 1982; 17: $37-49$.

30 Friedewald WT, Levy RI, Fredrickson DS. Estimation of the concentration of low-density lipoprotein cholesterol in plasma, without use of the preparative ultracentrifuge. Clin Chem 1972; 18: 499-502.

31 Rasmussen K, Moller J, Lyngbak M, Pedersen AM, Dybkjaer L. Age- and gender-specific reference intervals for total homocysteine and methylmalonic acid in plasma before and after vitamin supplementation. Clin Chem 1996; 42: 630-636.

32 Clarke R, Lewington S, Donald A, Johnston C, Refsum H, Stratton I et al. Underestimation of the importance of homocysteine as a risk factor for cardiovascular disease in epidemiological studies. J Cardiovasc Risk 2001; 8: 363-369.

33 Clarke R, Smith AD, Jobst KA, Refsum H, Sutton L, Ueland PM. Folate, vitamin B12, and serum total homocysteine levels in confirmed Alzheimer disease. Arch Neurol 1998; 55: 1449-1455.

34 McCaddon A, Davies G, Hudson P, Tandy S, Cattell H. Total serum homocysteine in senile dementia of Alzheimer type. Int J Geriatr Psychiatry 1998; 13: 235-239.

35 Obeid R, Herrmann W. Mechanisms of homocysteine neurotoxicity in neurodegenerative diseases with special reference to dementia. FEBS Lett 2006; 580: 2994-3005.

36 McCully KS. Vascular pathology of homocysteinemia: implications for the pathogenesis of arteriosclerosis. Am J Pathol 1969; $\mathbf{5 6}$ 111-128.

37 Bostom AG, Silbershatz H, Rosenberg IH, Selhub J, D'Agostino RB, Wolf PA et al. Nonfasting plasma total homocysteine levels and all-cause and cardiovascular disease mortality in elderly Framingham men and women. Arch Intern Med 1999; 159: $1077-1080$

38 Kloppenborg RP, van den Berg E, Kappelle LJ, Biessels GJ. Diabetes and other vascular risk factors for dementia: which factor matters most? A systematic review. Eur J Pharmacol 2008; 585: $97-108$.

39 Bottiglieri T, Laundy M, Crellin R, Toone BK, Carney MW, Reynolds EH. Homocysteine, folate, methylation, and monoamine metabolism in depression. J Neurol Neurosurg Psychiatry 2000; 69: $228-232$.

40 Sai X, Kawamura Y, Kokame K, Yamaguchi H, Shiraishi H, Suzuki $\mathrm{R}$ et al. Endoplasmic reticulum stress-inducible protein, Herp, enhances presenilin-mediated generation of amyloid beta-protein. J Biol Chem 2002; 277: 12915-12920.

41 Vafai SB, Stock JB. Protein phosphatase 2A methylation: a link between elevated plasma homocysteine and Alzheimer's disease. FEBS Lett 2002; 518: 1-4.

42 Perez FP, Ilie JI, Zhou X, Feinstein D, Jurivich DA. Pathomolecular effects of homocysteine on the aging process: a new theory of aging. Med Hypotheses 2007; 69: 149-160.

43 Armitage JM, Bowman L, Clarke RJ, Wallendszus K, Bulbulia R, Rahimi $\mathrm{K}$ et al. Effects of homocysteine-lowering with folic acid plus vitamin B12 vs placebo on mortality and major morbidity in myocardial infarction survivors: a randomized trial. JAMA 2010 303: 2486-2494. 
44 Clarke R, Harrison G, Richards S. Effect of vitamins and aspirin on markers of platelet activation, oxidative stress and homocysteine in people at high risk of dementia. J Intern Med 2003; 254: $67-75$.

45 Connelly PJ, Prentice NP, Cousland G, Bonham J. A randomised double-blind placebo-controlled trial of folic acid supplementation of cholinesterase inhibitors in Alzheimer's disease. Int $J$ Geriatr Psychiatry 2008; 23: 155-160.

46 Lewerin C, Matousek M, Steen G, Johansson B, Steen B, NilssonEhle H. Significant correlations of plasma homocysteine and serum methylmalonic acid with movement and cognitive perfor- mance in elderly subjects but no improvement from short-term vitamin therapy: a placebo-controlled randomized study. $A m \mathrm{~J}$ Clin Nutr 2005; 81: 1155-1162.

This work is licensed under the Creative Commons Attribution-NonCommercialNo Derivative Works 3.0 Unported License. To view a copy of this license, visit http://creativecommons. org/licenses/by-nc-nd/3.0/ 